\title{
THE ROLE OF CONTENT AND LANGUAGE INTEGRATED LEARNING AT UKRAINIAN AND POLISH EDUCATIONAL SYSTEMS: CHALLENGES AND IMPLICATION
}

\author{
Mariya Leshchenko \\ Jan Kochanowski University in Kielce, Poland \\ darlyngpetra@gmail.com
}

\author{
Yuliana Lavrysh \\ National Technical University of Ukraine "Igor Sikorsky Kyiv Polytechnic Institute”, Kyiv, Ukraine \\ yulavrysh@gmail.com
}

Kateryna Halatsyn

National Technical University of Ukraine "Igor Sikorsky Kyiv Polytechnic Institute”, Kyiv, Ukraine galatsyn_kateryna@ukr.net

\begin{abstract}
At present, Ukrainian universities are immersed into current processes of internationalisation, academic mobility and engaging into a European context, that, consequently, give rise to numerous surveys on advanced pedagogical approaches to correspond the framework of general European language learning policy. The paper aims to describe and summarise the experience of Content and Language Integrated Learning implementation (CLIL) in Ukraine. With the view of objective assessment of the survey results, we considered comparing our experience, challenges and solutions with Polish universities experience since CLIL approach is widely used and made its own history with great outcomes in Poland. The qualitative data of our survey were gathered, evaluated and compared with those presented in published investigations of Polish experts. The key objectives are to identify operating CLIL models and strategies at Igor Sikorsky Kyiv Polytechnic Institute and to measure up functioning features of this approach by means of SWOT analysis. Moreover, the researchers disclose the approach advantages, drawbacks and recommendations for further discussion. In the paper, the authors also outline the peculiarities of ongoing coexistence and relation of English for Specific Purposes (ESP) and CLIL in tertiary education in terms of aims, tasks, resources, teachers' roles and outcomes. The research results show that ESP and CLIL are interrelated approaches, which both contribute to students' learning motivation as well as language and field-related content acquisition; CLIL is a key factor for universities to attract students and take high rates in educational ranking.
\end{abstract}

Keywords: CLIL; ESP; internationalisation of higher education; language learning; functional language; field-related content.

\section{Introduction}

Recent educational transformations in Ukraine are regarded as a response to the progress towards internationalisation of higher education. Among the key factors, which facilitated this shift, we consider a high demand for internationally recognised qualifications, increase in academic and workforce mobility, transnationalising of education, development of sustainable and standardised degree programmes and quality assessment systems. All mentioned changes have disclosed drawbacks of modern Ukrainian system of English language teaching and increased appeal for the language skills acquisition across all stages and sectors of education. As a possible way to upgrade Ukrainian universities, to attract more overseas students and to take high ranking positions, we suggest the expanded use of Content and Language Integrated Learning (CLIL) approach which is widely accepted and implemented in European universities.

CLIL is a dual-focused approach which appeared due to the appeal of the modern labour market and economy. Its dual character is a cognitive challenge for teachers as well as for students as it is substantiated by the combination of language teaching with the context. The key factor of the approach is a language learning process, which leads to communication, and content learning through authentic situations and materials. Despite the immense popularity of CLIL in the world, there are still few university programmes in Ukraine, which suggest teaching content subjects through the medium of a foreign language. In our opinion, the provision of CLIL is limited due to the lack of linguistically literate subject teachers as well as the absence of pedagogical guidelines on how to conduct effective CLIL teaching. There are also limited possibilities of continuous professional development for subject teachers, the system of assessment has not been yet developed.

Nevertheless, the analysis of the experience of CLIL approach implementation in other countries allows us to identify its features and evidence-based outcomes. We have chosen Polish universities as an example of successful CLIL implementation, which in the pre-CLIL period had the same educational problems and challenges that we are experiencing now. In addition, observing their results, we ensure the great educational potential provided by this approach. 
The objectives of the research are to define CLIL operating models implemented in Poland, examine their operational features and implementation in Ukraine, and define the threads and perspectives of CLIL in Ukraine by means of SWOT analysis. The study should be considered as an overview of practice aimed at the endorsement of beneficial CLIL models development across the university curricula. Moreover, the authors suggest a number of recommendations for successful implementation of the approach regarding teachers, students, materials and resources.

The qualitative methods used to conduct the study included SWOT analysis, literature reviewing, classes observations, teachers interviewing and discussions.

\section{Theoretical framework}

CLIL in higher education is considered as an umbrella term for those strategies and approaches used in order to foster the learning of the content through the language (Coyle et al., 2010). These approaches are English for Specific Purposes, English for Academic Purposes, Content-Based Learning, Content-Based Instruction, Cognitive Academic Language Learning, multilingual learning etc. They are joined under one common concept that it is impossible to obtain knowledge without the language of a subject, and at the same time, that language learning effectiveness rises with using authentic and relevant to students' specialism context. Therefore, students achieve mastery in extra-lingual professional context through the language media. The language learning is based on the curriculum of a non-language subject. It means that the acquirement of the language content is driven by the content and corresponds to the methods and themes of a non-language subject whereas language skills formation is a supplementary process.

As any pedagogical technology, CLIL has its own learning objectives and outcomes. The Language Network for Quality Assurance project, funded by Erasmus programme (2013), was aimed at the provision and implementation of CLIL throughout the world in cooperation with 60 partner universities. According to the developed Frame of Reference, as a result of the project, CLIL students and teachers are able to:

- accept and mediate between the languages and cultures in the field-related domain;

- appreciate the features and principles of international multicultural teamwork;

- apply target language for professional communication conventions;

- recognise the importance of continuous professional development.

The mentioned above objectives are closely connected and derive from the basic CLIL principles, defined by the world known experts of CLIL (Coyle, Hood, \& Marsh, 2010; Cenoz, 2015): the linguistic analysis of the content material should be performed to ensure the development of language; the language of the content should be accessible and understandable to provide mutual interaction; cognition competence should prevail over linguistic competence; intercultural perception is essential for CLIL. These principles outline the paramount features and millstones of CLIL. However, we can point out some CLIL principles, which meet the needs of Ukrainian universities. The Ukrainian researcher Nozhovnik (2012) describes such principles: functional language features should be taught parallel to the content since the language is used for communication as well as for leaning; language integrates into the general curricular of higher professional education; students' academic performance improves due to the learning of "real" language represented via authentic resources. In our opinion, these principles constitute the frame of CLIL implementation in Ukraine and they can be taken into account while developing educational materials for such classes.

Taking into consideration research of CLIL experts (Gierlinger, 2013; Kampen, Meirink, Admiraal, \& Berry, 2017), we can trace transformations of the approach through the learning process from the disciplinebased teaching language to dual-focused CLIL. The foreign-language mediated education originates from the partial CLIL stage when the contact between the language and content is occasional and unsystematic (visiting expert lectures, participating in conferences) and there is no systematic collaboration between the language and subject teachers. The next stage is the adjunct CLIL- or ESP teaching. It is represented by language-oriented classes targeting specific disciplines. The language learning is based on the authentic content materials aimed at acquiring basic functional language and is taught by a language teacher without deep professional field-related knowledge. At the top of the scale, there is the true dual-focused CLIL approach, which implies parallel learning of the language and content taught by linguistically and pedagogically conscious teachers or by a team of language and subject specialists. Such close collaboration might give a rise to the pedagogical, linguistic and personal growth of teachers' competencies and will be of great help in formulating learning outcomes and assessment criteria in order to distinguish content and language mastery. Moreover, Moor and Dooly (2010) claim that true dual-focused CLIL is employing a new paradigm of a student's role, which is transformed from the language learner to the language user.

In spite of understanding the nature, principles, features of CLIL, a lot of teachers and curricular planners are afraid of the approach implementation, feel confused, and do not clearly understand how to 
establish an equal partnership between language and content. The solution is the 4Cs conception model, suggested by the authors of a book "CLIL (Content and Language Integrated Learning)" by Coyle, Hood, \& Marsh, 2010. The term "4Cs" stands for the content, cognition, communication, and culture and these factors are considered as a basis for successful CLIL classes planning. So, with a view of CLIL class planning, a teacher should first choose the content focus and learning outcomes, then it is necessary to undertake main cognitive skills to be developed (high order thinking skills), the third step is language functions, structures, exponents selection to provide the communication in vehicular language. The last step is developing openness to foreign culture and ideas, citizenship awareness, interest in searching the "self" and understanding others.

Some aspects of the content integration were investigated by Taillefer (2013) who states that language and non-language content do not dominate of one over the other; it is in a balance, so that students could share their efforts and interests equally. Speaking about the aspects of communication, it is obvious that the language needed depends on the content. The researcher Gierlinger (2013) identifies three analytical approaches toward the issue of language to be taught: the language of learning (identification of basic concepts, constructions and the language corpus to be learnt); the language for learning (exponents and chunks for discussions, summarising, agreement, disagreement, clarifying etc.); the language through learning (functional language acquired because of CLIL classes). As we underscore, the main idea of this division is that in terms of CLIL the communication and language learning go far beyond just learning grammar rules or vocabulary.

As the literature suggests, the roles of teachers in the process of CLIL adjustment is crucial. Experts outline the list of requirements for the content and language teachers as well (Martin, 2015; McDougald, 2016; Ribeiro, 2016). Thus, content teachers, as carriers of field-related language discourse and communication patterns, should demonstrate a high level of communicative competence and teach with the same impulse and attitude as they do when they teach in native language: be sensitive to students' level of comprehension, tolerant to multicultural issues, use paraphrasing, explain in simple language, be ready to adopt innovative interactive pedagogical techniques, materials, or visuals etc. Language teachers, in their turn, should also accept innovations regarding the language and communication learning impact on professional knowledge acquiring process. With this in mind, we have to recognise the students' professional needs, reconsider the balance between the fluency and accuracy, and create interdisciplinary collaboration.

But the key pedagogical competences are described in the European Framework for CLIL Teacher Education (Mehisto,2012; Wolff, 2012; González, 2013). They comprise individual critical reflection to assess one's own needs and competences; acceptance of CLIL core concepts, principles, methods and models; high level of language and content knowledge to foster personal cognitive development; skills of classroom management, pedagogical methods of teaching and assessment; engagement into CLIL research.

Not only teachers have to upgrade their skills, but students also should have the particular background, as Cummins (2013) called it CALP: cognitive academic language proficiency. These skills include necessary competence in academic listening, academic reading sub-skills (skimming, scanning, graphs reading etc.), academic writing using high-precision subject-specific vocabulary, functional language and exponents, discussions and presentations conducting competence, critical thinking skills (defining classifying, comparing, contrasting, etc). This requirement implies grounded and substantial previous training, which is supposed to be done by ESP teachers during first years of studying at university. CLIL is recognised as being a derivative from ESP practices or ESP alternative method; however, it goes far beyond ESP. It is critical to differentiate the functions of CLIL and ESP teachers: the first group is focused on the content learning and field-related concepts, whereas ESP teachers learn necessary language skills (how to communicate effectively, how to prepare proposal or presentation, how to write a report) that are crucial for successful professional knowledge acquisition. Thus, we strongly believe that language teachers and content teachers should be co-researchers to provide students with meaningful course design, interactive classes and advanced level field-related accomplishment.

There are a lot of meaningful arguments facilitating CLIL implementation, but we have to understand that CLIL can be effectively applied only if university policy accepts all necessary changes in terms of structural, organisational, and pedagogical transformations. In our further study, we will disclose the potential of CLIL models implementation within the tertiary level of education in Ukraine and will share the experience we obtained on the way to the dual-focused CLIL. 


\section{Polish CLIL experience}

Due to the global integration into the European Union, the issue of modern, innovative ways of language learning is of a great concern for mostly all non-English speaking countries, because foreign language knowledge opens the gates to the European integration. The European Council resolutions on language learning require the knowledge at least of two languages in order to live and work together in one community. CLIL approach meets this requirement but it causes the reorganisation and restructuring of the whole educational system of foreign languages learning. Initially, CLIL was introduced through bilingual education for schools. The resolution of European Council in 1995 declared the onset of CLIL implementation and announced the call for research and study of new educational practices, which can enhance CLIL implementation. It gave a huge rise to CLIL programmes development, which are in the mainstream of foreign languages teaching research nowadays.

CLIL approach in Poland also derived from the bilingual education. Today not only English, but German, French, Spanish and Italian are the languages of instruction in Poland. At universities, this approach is presented on the Baccalaureate and Masters programmes, which have their own pedagogy, assessment system, resources database. The main subjects taught in English at universities are Computer Sciences, Building Industry, Chemistry, Geography, Mathematics, Law and Medicine. In order to be enrolled in such programme students pass their final school exam Matura in English.

The Eurydice survey (2006) "Content and Language Integrated Learning (CLIL) at School in Europe" is considered to be the first experience of CLIL application in Poland. The key objectives of the survey were to identify the most suitable methods and models of bilingual learning in Poland. The main challenges of that time were: lack of methodologically developed activities for CLIL, not enough constructive collaboration, misunderstanding of principles and language and content teachers' role in the CLIL process, since ESP teachers' duty was just to translate material and prove certification. However, they did not give up the idea of CLIL application and the results are very impressive now.

Having analysed a number of scientific finding on the topic of the research, we have found four main models of CLIL implementation in Poland (Czura, Papaja, \& Urbaniak, 2009).

The first model is considered as a teacher-based learning with extensive English language medium instructions using active students' involvement into pair or group work. A lecturer speaks mainly in English with some terminology into Polish. This model is divided into two types: with single and dual focus. CLIL learning with a single focus implies only content learning, whereas dual-focused model suggests learning of both language and content. However, the degree of focus varies and more frequently, it is the content that prevails.

The second model is a teacher-based learning with partial English medium instructions (codeswitching) with limited students' involvement. There is an equal share of language amount division during the process of teaching. This model is also subdivided into two types: single and dual-focused with a lot of switching between two languages.

The third model is a teacher-based instruction with limited English medium instruction. Polish language dominates over English and there is a lot of switching. The subdivision into types is the same as in previous two models.

The fourth model combined learning model with specific English medium instruction. Both languages are used in the learning process. Nevertheless, there is a significant difference in educational techniques applied, which explains the term "combined model". This model suggests series of lessons devoted to a specific content initially taught in Polish and then followed by lessons conducted in English aimed at revising material but through English instructions. As a modification of material recapitulating, taught earlier in Polish, teachers propose students to prepare projects or presentation in English. Some teachers apply an interesting deviation in the frame of this model. The educational materials can be written only in English, but lessons might be conducted in Polish and vice versa. Another variant of the model is the opposite one when initially the content is suggested in English and conclusions are made in Polish.

Based on Polish experience of CLIL implementation, the expert on CLIL in Poland Papaja (2014) gives the following recommendations:

- teachers should accept that CLIL is a combination of content and language, which means academic communication should be conducted in English;

- provide teacher-student interaction rather than academic explanation in a monologue, teachers should pay attention to the share of their communication, students also should speak, so the amount of teachers' speaking time is better to shorten;

- limit the usage of mother language; 

students.

- use educational and scientific resources written in English, so that to have enough material to suggest

To sum up, we can state that CLIL as a concept has completely changed the bilingual learning system in Poland. It attracts foreign students, forces teachers to carry out professional development, provides students and teachers with opportunity to communicate with their colleagues from abroad and share the most innovative experience, to carry out joint research, to enter Master level abroad, to enhance the quality and quantity of scientific publications and international conferences and exchange programmes participation.

\section{CLIL in Ukraine}

In Ukraine, there is not any form of national-wide language policy for universities. Therefore, universities develop their own language policy and most of them are trying to implement at least some elements of CLIL but our efforts and suggested classes are still at the partial or pre-CLIL stage implementation.

In order to give an objective evaluation of Ukrainian CLIL context, to substantiate the necessity of its implementation, to identify advantages and drawbacks, we decided to use SWOT (strengths, weakness, opportunities, threats) analysis. According to results of our observations, interviews and personal experience, we have established the following:

CLIL strengths: facilitation of university internationalisation; rising the prestige of the university and ranking positions by inviting foreign students and teaching staff; increasing the quality and quantity of scientific papers publications in international journals; stimulating students' motivation to learning; formation of tolerant attitude towards multilingual and multicultural society.

CLIL weaknesses: not clear and non-standardised assessment system; lack of interdisciplinary collaboration; low level of self-confidence as a result of teachers' and students' low level of language; not enough scientific authentic literature resources in the library.

CLIL opportunities: financial benefits for universities, high ranking positions; international recognition; enhancing the employability of students; raising of academic standards; high level of academic internationalisation.

CLIL threads: organisational changes associated with interdisciplinary connections; damping down the quality of content and simplifying it because of the differences in learners' and teachers' linguistic abilities; students' demotivation due to unclear tasks and inability of a teacher to explain it in a simple way; teachercentred approach as learners may be afraid of communication and a teacher is in the centre of interaction.

The performed analysis is a helpful tool for developing and providing a strategy of CLIL implementation, submitting directions for weaknesses strengthening and threads overcoming. The experience of our university demonstrates the efforts and measures taken to promote the CLIL implementation.

CLIL approach is one of the priorities at Igor Sikorsky Kyiv Polytechnic Institute as it facilitates the processes of internalisation and globalisation in terms of European educational community entrance. The university accepted the dual-focused model of the teaching suggested only in the English language. The process of CLIL implementation faced numerous challenges: students' low language competence level, diversity of subjects, combination of educational resources and professional needs, lack of English speaking subject teachers, psychological barriers of teachers and students to acquire professional knowledge in English, insufficient amount of materials in English and limited time for cooperation of language teachers and subject teachers. However, nowadays more and more departments suggest courses in English and more subject teacher conduct lectures and seminars in English. Thus, we are at an intermediate stage form preCLIL to the partial CLIL stage. The transition was made due to successful cooperation of English teachers and subject teachers through joined seminars, language courses and development of learning contentlanguage courses for students where subject teachers suggested topics for presentations or projects, problembased tasks and material for data analysis. At the end of the Bachelor or Master degree students are able to prepare their scientific diploma project in English and present it to the examination board consisting of subject teachers and language teachers as well. PhD students are supposed to prepare an article in English on the topic of their research and present it on the exam.

However, we have to mention that the level of teaching CLIL at the university needs mastering and improvement. The key problems arise due to some false assumptions that to teach CLIL, it is enough just to change the language in which the classes are taught. Because of special CLIL training absence, content teachers often omit the main goal of the approach and concentrate on lecture-type classes with the focus on the content but not on the language. The quality of student-teacher communication is poor because teachers do not know how to combine these notions: language and content. Consequently, there is a risk that such classes will become boring for students, the subject content learning will worsen, students become 
demotivated that will lead to poor learning outcomes. The main cause of this possible situation is not in English language or its level but in the way teachers introduce classes in English. Among main drawbacks of the approach, we can point out that it is a time-consuming process, requiring more thinking and concentration from both teachers and students, so teachers are often frustrated how to teach and they just read the lecture and it becomes boring.

Also, taking into account the results of our observation, we have made a conclusion that language level is not the main problem in CLIL classes but the level of subject teachers' teaching proficiency is. Subject teachers are proficient engineers, technicians or IT specialists, but without sufficient level of pedagogical methods accomplishment. The only way to solve this problem at this time is carrying out workshops and seminars, conducted by teachers of ESP department, for content teachers how to bridge the gap between the language and content teaching. During such workshops ESP teachers and content teachers plan CLIL classes together, share experience how to choose the material and introduce it to students. The main goals of the seminars are not only to rise English level awareness, but also to demonstrate and share CLIL activities to make classes more interactive.

We suggest the four basic types of activities (Ball, Kelly, \& Clegg, 2016) which can facilitate students' academic achievements despite the lack of linguistic experience and resources:

1. Activities to enhance peer communication;

2. Activities to develop speed reading strategies (skimming, scanning, etc.);

3. Activities for the formation of productive skills (oral and written);

4. Activities that involve high order thinking skills.

Among the most used and effective activities we can list information-gap crosswords or gap-filling in the texts (connection of content and language); finding necessary information in authentic text without detailed reading or choosing more important and less important facts (reading strategies); "Presentations, practice, production" (PPP) on content topics (productive skills) or, as a variant of this activity, is "Engage, study, activate" (ESA) which involves the completion of a survey or a WebQuest (critical thinking skills).

Considering CLIL models implementation employed at Polish universities, we have identified three main models used by Ukrainian teachers. We have analysed them in order to point out main problems and suggest the way of their solution through the Polish experience. These models are:

1. Adjunct CLIL model is used by academics confident in English with the experience

teaching abroad or by invited foreign teachers. During such classes, we observed English commentaries on formulas or visuals, complete interaction in English continuous comprehension check, permitting questions for clarifications, adapting English for students' needs (pauses, slowing down, spelling clarifications). It is obvious, that this strategy corresponds to CLIL meaning and is the most beneficial for students. Nevertheless, such classes are in a limited number owing to lack of teachers who are able to conduct them. Another drawback is that the content dominates the language, main tasks are focused on content accomplishment, not language learning. According to teachers opinion, they do not think that it should be done and do not know how to combine it. As they report: their main purpose is not to teach English but to ensure content acquisition. The best linguistic strategy they suggest is vocabulary lists handed out to students before the lecture. Therefore, this statement confirms the fact that such teaching strategy is not true CLIL approach, which underlines the integration of language and content.

2. Partial CLIL model with code switching strategy is the one, which is widely used. Teachers use the Ukrainian language to support communication, they provide a summary in Ukrainian, allow students to answer in Ukrainian to questions asked in English, explain technical terms in a native language, provide bilingual dictionaries. This strategy is close to the second model applied in Polish universities. The reason for this lies in teachers' not sufficient language literacy or confidence. However, in order not show this to students, teachers use difficult overloaded with field-related terms texts, without previous students preparation, and read it from papers or slides. If students ask for the clarification, teachers just translate the term or refer students to the dictionary, because they do not want to waste time on "language problems". It greatly demotivates students as they cannot understand the content and fail the home tasks completion.

3. The last model is a combined strategy with using visual-aid and textual support, used by teachers who recognise their linguistic difficulties but are eager to develop and are not afraid of collaboration with students. It is a great idea to use students as a source of language knowledge, especially if students demonstrate a high level of language abilities. The possibility for students to participate in a lecture as partners stimulate their academic activity and teachers do not feel frustrated in case of language misunderstanding. Students help to explain, clarify or even paraphrase the texts or definition. The amount of English language usage varies from the topic of the lesson, resources and students previous background. The variability of language usage is rather extended. The same as in Poland, teachers may suggest visual support 
or textual handouts in Ukrainian, or refer students to Ukrainian textbooks, another variant is pre-teaching material in a native language during the previous lecture and recapitalising it in English during seminars.

The analysis of these models exposes the main problems while CLIL application. Nevertheless, we consider that out teachers are trying to overcome difficulties and suggest creative and meaningful strategies. Providing the fruitful language and content teachers' cooperation, language, resources and methodological support our university will contribute to the further improvement and mastering.

Having discussed the advantages of CLIL implementation at the university, teachers considered this approach as a useful tool for professional and personal growth, a method for communication enhancing, provision of access to scientific sources in English, a possibility to participate in international conferences, publishing in scientific journals and representing the results of their research in order to share ideas and get critical feedback.

In spite of the linguistic difficulties and cognitive challenges, students are enthusiastic toward this approach implementation as it corresponds to their professional wants and needs. The favourable attitude evidences students' recognition of time and labour market requirements, students treat CLIL as a tool for achieving their career goals.

The evidence from this study points towards the idea that our teachers require some pedagogical recommendations in order to facilitate the CLIL principles integration into the learning process. We fully support Polish experts (Czura, 2009, Papaja, 2014) who state that a teacher should understand the relationship between learning situation under the exploration by students and overall goals of the contextbased learning curriculum. It is necessary to bear in mind that a tutor serves as a learning process guide rather than a content expert for students oriented towards learning language and content. It implies using active learning environment thereby stimulating students to discover what they do not understand, determine what they need to learn, find reliable resources to match students' needs, synthesise information in relation to the language and content acquisition. If a teacher is aimed at conducting outcome-oriented, reflective, constructive and dynamic CLIL lessons it is recommended to:

- think over preferable language strategy used while classes;

- prepare educational resources and visual supports in English;

- adjust their methodology to students' level of comprehension;

- to apply task-based and learner-centred resources;

- challenge rather than confirm all students' conclusions;

- encourage students to express their ideas or insights in English;

- use facilitative communication skills;

- foster discussions and debates;

- constructively explore together with students how to reduce negative effects and misunderstandings.

Despite great teachers' responsibility for CLIL approach implementation, we should not forget about students' needs and opinion, which can be of great assistance for improvements and negative effects elimination. To ensure such mutual activity, it is important to determine what students really need to pursue as learning issues within suggested curricular. In other words, we have to consider students' instrumental motivation which involves material wealth and career opportunities (Saienko, 2017). The results of students' attendance, level of preparation and academic assessment are crucial indicators of the process dynamics. We observe evidence of their success; students' autonomy facilitation helps to overcome a lot of problems which might arise. Students will demonstrate respect and will take responsibility for their own learning progress in the frame of CLIL classes in case if they are allowed to:

- identify learning issues within a given authentic real-life situation;

- determine assignments needed for pursuing the learning issues;

- share what has been learned and synthesised during the class;

- appraise credibility of information shared during classes according to sources provided by teachers;

- provide feedback on teachers' performance;

- develop together with a teacher clear and objective criteria for the assessment.

Comparing results of Polish implementation process and Ukrainian one, we can clearly see the goals and perspectives for our further research. The solutions to main issues can be taken from Polish experience, however, we, in Ukraine, have our own way and we are able to think up some new methods and strategies. Although, the greatest advantage of Poland is the national language learning policy for universities that provides support and resources at least at initial stages. 


\section{Conclusions}

Globalisation, internationalisation, multilingual citizenship and cultural diversity are inevitable parts of today's world. The world is turning into a mixed global village where all languages and cultures are mixed. Educators have to accept the time challenges and CLIL is a kind of such timely and innovative response. As time passes we have to follow its pace and today a new kind of a content and language teacher is able to inspire and guide students. We absolutely agree with Smit \& Dafouz (2012) who state that process of language learning will become better in the future, as a new generation of CLIL students and teachers appears in higher education.

The main conclusion that can be reached from the information presented so far is that CLIL is the tool, which will prepare our students for future career and satisfy their wants and needs. However, the paucity of proper methodological support and training, as well as complex linguistic context with particular requirements, teachers' resistance and false assumptions, impede the implementation of the approach in Ukrainian universities. One of the possible solutions is the collaboration of content and language teachers. From our experience, we can state that pure CLIL is not enough sufficient without ESP support. Only the combination of these approaches can supplement and enhance students' language proficiency and strengthens content teacher's language awareness.

In our humble opinion, we believe that CLIL brings a lot of innovations into universities: rethinking of traditional language learning strategies, transformations in conducting field-related lectures, changes in students' attitude towards language and content learning, facilitation of students' autonomy, metacognitive students' skills development, enhancing teachers continuous professional development. Nevertheless, a lot of work should be done so that CLIL will become sustainable and traditional approach to foreign language learning.

\section{References:}

Ball, P., Kelly, K., \& Clegg J. (2016). Oxford Handbooks for Language Teachers: Putting CLIL into Practice. Oxford University Press.

Cenoz, J. (2015). Content-based instruction, content, and language integrated learning: the same or different? Language, Culture and Curriculum, 28(1), 8-24 https://doi.org/10.1080/07908318.2014.1000922

Content and Language Integrated Learning (CLIL) at School in Europe (2006). Retrieved February 12, 2018, from Eurydice website http://www.indire.it/lucabas/lkmw_file/eurydice/CLIL_EN.pdf

Coyle, D., Hood, P., \& Marsh, D. (2010). Content and language integrated learning. Cambridge: Cambridge University Press.

Cummins, J. (2008). BICS and CALP: Empirical and theoretical status of the distinction. In Street, B. V., \& Hornberger, N. (Eds.), Encyclopedia of Language and Education, 2: Literacy (pp.71-83). New York: Springer Science + Business Media LLC. Retrieved February 23, 2018, from https://www.slideshare.net/suareze986/bics-and-calp-empirical-and-theoretical-statusof-the-distinction

Czura, A., K. Papaja, \& M. Urbaniak (2009). Bilingual education and the emergence of CLIL in Poland. In D. Marsh, P. Mehisto, D. Wolff, R. Aliaga, T. Asikainen, M.J. Frigols-Mart'1n, S. Hughes, and G. Lange' (Eds), CLIL practice: Perspectives from the field (pp.172-8). Finland: University of Jyva"skyla.

Fürstenberg, U. \& Kletzenbauer, P. (April, 2015). Language-sensitive CLIL teaching in higher education: Approaches to successful lesson planning. ELTWorldOnline.com. Special Issue on CLIL. Retrieved February 09, 2018, from http://blog.nus.edu.sg/eltwo/?p=4791

Gierlinger, E. (2013). The languages for CLIL Model. Retrieved February 27, 2018 from http://clilingmesoftly.wordpress.com/clilteachers-tl-competence

González Ardeo, J. M. (2013). (In)compatibility of CLIL and ESP courses at university. Language Value, 5 (1), $24-47$. http://dx.doi.org/10.6035/LanguageV.2013.5.3

Kampen, E., Meirink, J., Admiraal, W., \& Berry, A. (2017). Do we all share the same goals for content and language integrated learning (CLIL)? Specialist and practitioner perceptions of 'ideal'CLIL pedagogies in the Netherlands. International Journal of Bilingual Education and Bilingualism, 21 (2), 1-17. https://doi.org/10.1080/13670050.2017.1411332

Language Network for Quality Assurance (2013). Retrieved Ferbruary 05, 2018, from http://ec.europa.eu/programmes/erasmusplus/projects/eplus-project-details/\#project/c1752e7c-6a49-4ed7-a89c-cf32e30d245e

Marsh, D. (2012). Content and Language Integrated Learning (CLIL). A Development Trajectory. University of Cordoba. Retrieved February 20, 2018, from: helvia.uco.es/xmlui/bitstream/handle/10396/8689/2013000000658.pdf?sequence=1

Martín, M.A. (2015). Teacher education for content and language integrated learning: insights from a current European debate. Revista Electrónica Interuniversitaria de Formación del Profesorado, 18 (3), 153-168. http://dx.doi.org/10.6018/reifop.18.3.210401

McDougald, J.S. (2016). CLIL Approaches in Education: Opportunities, Challenges, or Threats? Latin American Journal of Content and Language Integrated Learning, 9(2), 253-266. http://dx.doi.org/10.5294/laclil.2016.9.2.1

Mehistro, P. (2012). Criteria for producing CLI learning material. Encuentro, 21, 15-33. Retrieved February 20,2018 from http://www.encuentrojournal.org/textos/3.\%20Mehisto_rev.pdf

Moore, E. \& Dooly, M. (2010). How Teacher Trainees Negotiate Language, Content, and Membership in a CLIL Science Education Classroom at a Multilingual University. Journal of Language, Identity, and Education, 9, 58-79. http://dx.doi.org/10.1080/15348450903523591

Nozhovnik, O. (2012). Content and Language Integrated Learning in Courses of Foreign Languages for Specific Purposes at Tertiary Professional Schools: Theoretical Basics and Advantages of Implementation. Zbirnyk naukovyh prats Berdyanskogo Derzchavnogo Pedagogicheskogo universitetu, 3, 23-35. 
The role of content and language integrated learning (CLIL) at Ukrainian and Polish educational systems: challenges and implication

Papaja, K., (2014). Focus on CLIL: A Qualitative Evaluation of Content and Language Integrated Learning (CLIL) in Polish Secondary Education. Cambridge Scholars Publishing. Retrieved January 29, 2018, from http://www.cambridgescholars.com/download/sample/61664

Paran, A. (2013) Content and Language Integrated Learning: Panacea or Policy Borrowing Myth? Applied Linguistics review, 4(2), 317-342. https://doi.org/10.1515/applirev-2013-0014

Ribeiro, M. del C. (2016). Some Lessons Learned: The ReCLes.pt CLIL Project in Higher Education. An e-journal of Teacher Education and Applied Language Studies, 6(1), 20-37. https://doi.org/10.1515/eteals-2016-0002

Saienko, N. (2017). Cognitive development of students in foreign language acquisition. Advanced Education, 7, 4-8. https://doi.org/10.20535/2410-8286.77570

Smit, U. \& Dafouz, E. (2012). Integrating content and language in higher education. An introduction to English-medium policies, conceptual issues and research practices across Europe. AILA Review, 25, 1-12.

Taillefer, G. (2013). CLIL in higher education: the (perfect?) crossroads of ESP and didactic reflection. ASP: Multiplicités des approches en anglais de spécialité, 63, 31-53. Retrieved February 17, 2018, from http://journals.openedition.org/asp/3290

Wolff, D. (2012) The European Framework for CLIL Teacher Education. Synergies Italia, 8, 105-116. Retrieved February 20, 2018 from https://www.unifg.it/

Received: February 05, 2018

Accepted: April 30, 2018 